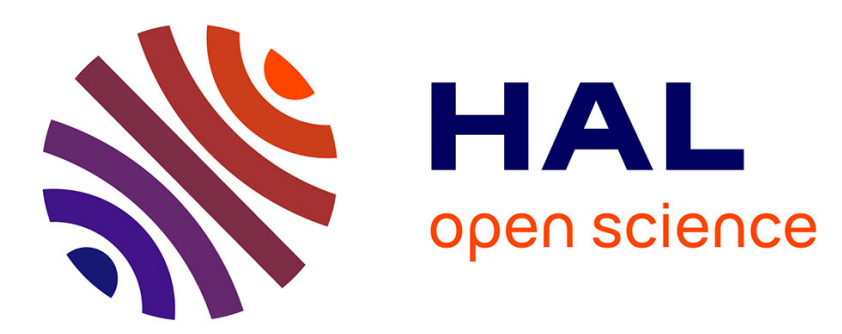

\title{
Waterbird communities adjust to climate warming according to conservation policy and species protection status
}

Elie Gaget, Thomas Galewski, Frédéric Jiguet, Isabelle Le Viol

\section{- To cite this version:}

Elie Gaget, Thomas Galewski, Frédéric Jiguet, Isabelle Le Viol. Waterbird communities adjust to climate warming according to conservation policy and species protection status. Biological Conservation, 2018, 227, pp.205-212. 10.1016/j.biocon.2018.09.019 . hal-01945528

\section{HAL Id: hal-01945528 \\ https: / hal.sorbonne-universite.fr/hal-01945528}

Submitted on 5 Dec 2018

HAL is a multi-disciplinary open access archive for the deposit and dissemination of scientific research documents, whether they are published or not. The documents may come from teaching and research institutions in France or abroad, or from public or private research centers.
L'archive ouverte pluridisciplinaire $\mathbf{H A L}$, est destinée au dépôt et à la diffusion de documents scientifiques de niveau recherche, publiés ou non, émanant des établissements d'enseignement et de recherche français ou étrangers, des laboratoires publics ou privés. 


\section{Waterbird communities adjust to climate warming according to conservation policy and species protection status}

Elie Gaget ${ }^{1,2}$, Thomas Galewski ${ }^{1}$, Fréderic Jiguet ${ }^{2}$ \& Isabelle Le Viol ${ }^{2}$

${ }^{1}$ Institut de recherche pour la conservation des zones humides méditerranéennes, Tour du Valat, le Sambuc, 13200 Arles, France

${ }^{2}$ Muséum National d'Histoire Naturelle, Centre d'Ecologie et des Sciences de la Conservation-CESCO - UMR 7204 MNHN-CNRS-UPMC, Station de biologie marine, 29900 Concarneau/43 rue Buffon, 75005 Paris, France

\section{Introduction}

Climate change is an ongoing major threat to biodiversity (Scheffers et al., 2016). Species can show various responses: from adaptation and range shifts to declines and sometimes extinction (Thomas et al., 2004). However, multiple concomitant stressors such as habitat loss, degradation and overexploitation that act at global scale (Maxwell et al., 2016) are suspected to limit adaptations to climate warming (Sirami et al., 2016; Currie and Venne, 2017). International conservation policies are major legal instruments designed to reduce or control global threats to biodiversity (Donald et al., 2007; Sanderson et al., 2016). By reducing some anthropogenic pressures, conservation policies should facilitate species adaptation to temperature increase (Trouwborst, 2011, but see Mazaris et al., 2013). Their efficiency against biodiversity erosion is strongly supported (Donald et al., 2007; Hoffmann et al., 2010; Gamero et al., 2017; Orlikowska et al., 2016; Sanderson et al., 2016), but how much they could facilitate climate change adaptation through distribution shifts remains poorly explored and generally disputable (Trouwborst, 2011; van van Teeffelen et al., 2015; Thomas and Gillingham, 2015). For example, the network of Natura 2000 sites across the European Union would be not sufficient to ensure connectivity and climate change adaptation of species (van Teeffelen et al., 2015), even if protected areas have been identified as promoting community adjustment to temperature increase, i.e. species turn-over depending on their thermic affinity (Gaüzère et al., 2016). This lack of assessment is largely due to a difficulty to evaluate the pattern of responses of a large number of species targeted by international conservation policies at large temporal and spatial scales (van Teeffelen et al., 2015).

Since 1967, Wetlands International (WI) has coordinated an annual international waterbird census one of the oldest international monitoring programs at a global scale, involving professionals and citizen volunteers. Data from this survey could be used to assess how conservation policies have affected the way wintering waterbirds respond to climate change (Amano et al., 2018). Within one of the largest world migration flyways, millions of waterbirds stopover or overwinter around the Mediterranean basin, a region which faces rapid environmental degradation (Newbold et al., 2015) as well as a substantial temperature increase (Mariotti et al., 2015; Guiot and Cramer, 2016). Because waterbirds depend on fragile ecosystems (Brinson and Malvárez, 2002), namely wetlands, and are important game species during winter and migration (Birdlife, 2013; Green and Elmberg, 
2014; Brochet et al., 2016), they require international cooperation to ensure their conservation across breeding and wintering distribution ranges (AEWA, 2015). Accordingly, they are one of the first taxonomic groups to have benefitted from the two main international conservation policies implemented in the western Palearctic: the European Union's Wild Birds Directive (BD, 79/409/EEC) and the Convention on the Conservation of European Wildlife and Natural Habitats, or Bern Convention (BC, 19.IX.1979). However, the effect of these policies on waterbird community adjustment to temperature increase remains undervalued (Pearce-Higgins et al., 2014).

Here, we examine the ability of waterbird communities wintering in the Mediterranean to adjust their species composition to temperature increase depending on the implementation of two international conservation policies, the Birds Directive and the Bern Convention. We use data on 145 species from the WI dataset, surveyed across 22 years and 2786 sites distributed within 22 countries with varying uptake of $\mathrm{BD}$ and $\mathrm{BC}$ conservation policies, for about 100 million birds counted. Using the Community Temperature Index (CTI, Devictor et al., 2008), we measure the thermic adjustment of waterbird communities to the increase of winter temperatures for each country, for groups of countries that are (i) Member States of the European Union, enforcing the $B D$, (ii) and/or Contracting Parties to the BC, (iii) or neither (hereafter "BD-BC", "BC", "No-BD No-BC"), (iv) and for the entire Mediterranean basin. We test whether the contribution of strictly and not strictly protected species to the CTI trends differs depending on their protection status. We hypothesize that i) CTI trends have increased inside, but not outside, the Member States of the EU (BD) and Contracting Parties to the $\mathrm{BC}$, ii) strictly protected species have contributed more to the $\mathrm{CTI}$ increase than not strictly protected species, and iii) this difference in contribution disappears in the countries which are not Member States of the EU or not Contracting Parties to the BC.

\section{Material and methods}

\subsection{Waterbird monitoring data}

Waterbird counts were performed as part of the International Waterbird Census (IWC), coordinated by Wetlands International (www. wetlands.org). Each year thousands of wetlands are monitored in January, providing one count event per site per year (Delany, 2005). We used data collected between 1991 and 2012 as they cover the whole waterbird community, not only Anatidae as during earlier periods. We focused on sites (wintering waterbird communities) located around the Mediterranean basin $\left(30^{\circ} \mathrm{N} ; 45^{\circ} \mathrm{N} ; 10^{\circ} \mathrm{W} ; 40^{\circ} \mathrm{E}\right.$; IPCC, 2014), distributed across 22 countries (Fig. 1). We retained only sites with at least two count events across the 22-year period. We then selected waterbird species as defined by the Agreement on the Conservation of African- Eurasian Migratory Waterbirds (AEWA, http://www.unep-aewa.org), totalling 145 species. Considering recent taxonomic changes and their complicated specific identification, Larus michahellis, L. cachinnans, $L$. armenicus and L. argentatus were all lumped into one 'species'. A total of 2786 sites have been retained, totalling 25,722 count events and 98.9 million birds. 


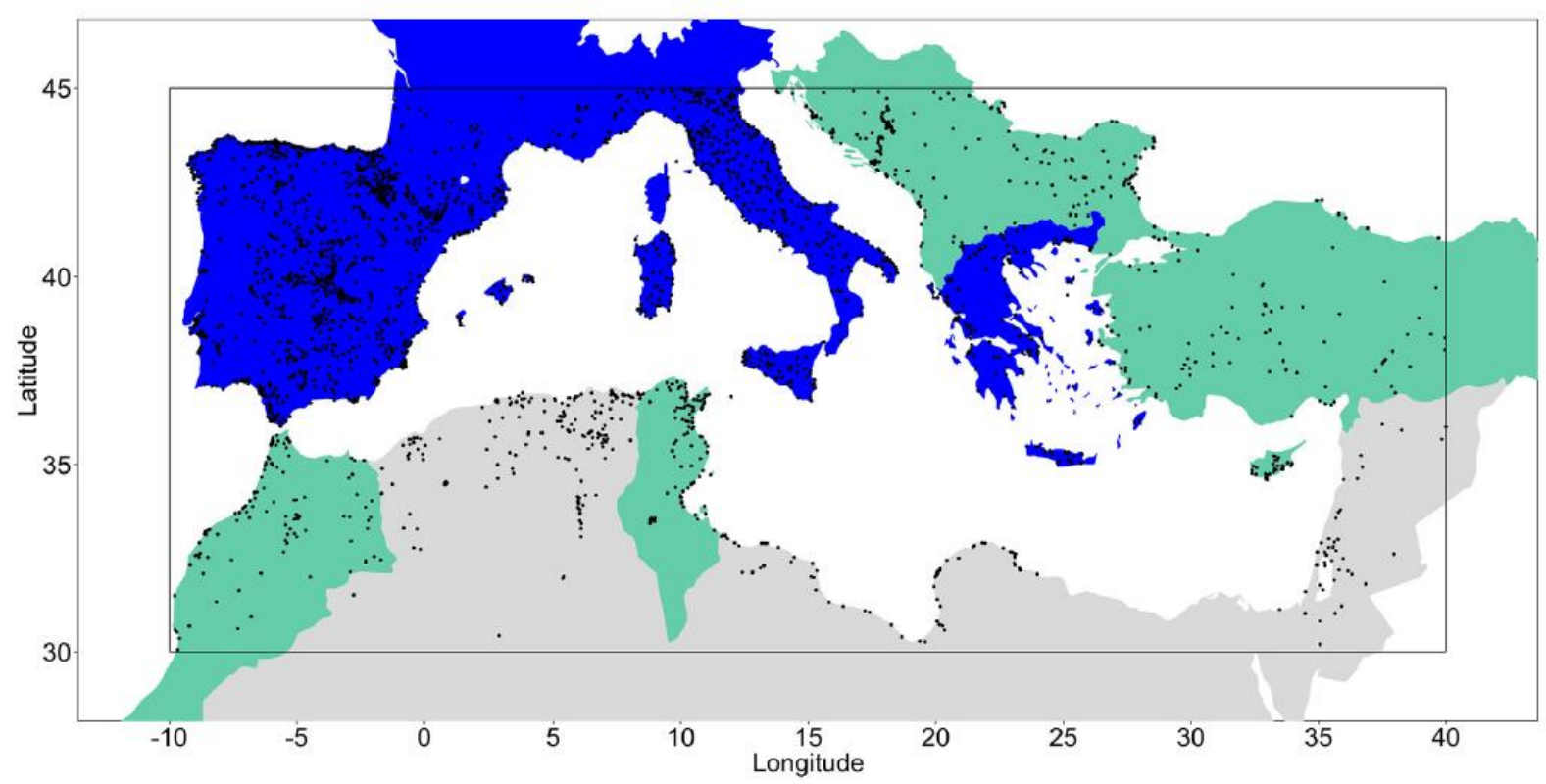

Figure 1: Mediterranean basin $\left(30^{\circ} \mathrm{N} ; 45^{\circ} \mathrm{N}\right.$ and $\left.10^{\circ} \mathrm{W} ; 40^{\circ} \mathrm{E}\right)$ divided in three legal contexts: the older European Union Member States enforcing the Birds Directive before the study period and contracting the Bern Convention ( $\mathrm{BD}-\mathrm{BC}$, in blue), the others Contracting Parties to the Bern Convention (BC, in green), and the nonContracting Parties (No-BD No-BC, in grey). Black points represent the counting sites $(n=2786)$.

\subsection{Species Temperature Index}

To calculate the Community Temperature Index (CTI), we used the Species Temperature Index (STI) which is a species-level measure of climate envelope based on the long-term average temperature over a species range (Devictor et al., 2008). This index is species dependent and, for each species, is a single value estimated across the entire geographical range. The STI is a straightforward niche metric to predict species responses to climate change (Devictor et al., 2012; Stuart-Smith et al., 2015) both for breeding and wintering birds (Godet et al., 2011; Devictor et al., 2012). We computed a winter STI following Godet et al. (2011) as the average of the mean temperature of January (19601990, WorldClim database http://worldclim.org/) across the wintering range of each species (winter range maps extracted from BirdLife International datazone, www.birdlife.org 2015) within the geographical zone defined by AEWA (Table S1).

In order to assess whether CTI trends were driven by an increase in warm-dwelling species and/or a decrease in cold-dwelling species, we calculated specific relative thermic originalities for each country. The "relative thermic originality" of a species is the distinctness of a species' thermic affinity (STI) compared to other species of the studied area (here country). It is obtained as the difference between the STI of a species $i$ and the average CTI of this area: warm-dwelling species have a positive relative thermic originality and cold-dwelling species have a negative relative thermic originality. For example, if the average CTI is +10 in a country and the STI of a species +15 , the relative thermic originality for this 'warm-dwelling' species in this country is +5 . Consequently a warm-dwelling species in France could be a cold dwelling species in Tunisia, like Aythya ferina or Calidris alpina. 


\subsection{Bird protection status}

We focused on two major international conservation policies dedicated at least partly to the protection of waterbirds: the Birds Directive (BD, 91/244/EEC) and the Bern Convention (BC, 19.IX.1979).

The Birds Directive and the Bern Convention aim to maintain all bird populations in a favorable conservation status "at a level which corresponds to ecological, scientific and cultural requirements, while taking account of economic and recreational requirements, or to adapt the population of these species to that level" (79/409/EEC, 19.IX.1979). Both BD and BC ensure bird conservation by two protection tools; direct protection from harvesting and indirect protection from habitat destruction or degradation. Hunting is prohibited for species listed in BD Annex I (BD-I) and BC Appendix II (BC-II), including no disturbance harming their favorable conservation status (exceptions are possible in particular cases). Conversely, species listed in BD-II and BC-III can be hunted, but their exploitation must be regulated in order to keep the populations out of danger (for example by closing seasons or temporary/local hunting ban). However, Member States of the EU (Birds Directive) can hunt the species listed in the BD-II part 2 only in indicated countries, and species listed in the BD-III require an assessment of their conservation status by the Commission before exploitation. Habitat conservation (through the designation of protected areas to creation of biotopes) is required for all bird species to ensure a favorable conservation status, particularly for species listed in BD-I and BC-II. Special attention is also given to areas regularly used by migratory birds (including those in BD-II and BC-III), notably wetlands and particularly wetlands of international importance.

Despite such potential differences in hunting legislation between species listed in BD-II (see above), we separated waterbirds in two categories. Species 'strictly protected', are species not hunted, listed in BD-I (56 species) and in BC-II (74 species). Species 'not strictly protected' regroup species listed in BD-II (44 species), the species not evaluated in the BD (45 species) and the species listed in BC-II (71 species). In countries where both BD and BC are applied, 63 species are 'not strictly protected'. In an EU Member State (see next paragraph), species were considered as 'strictly protected' if they were strictly protected at least by one of the two policies, like Aythya nyroca and Vanellus spinosus (protected in BD only). Three species are listed both in BD-I and BD-II (Anser albifrons, Philomachus pugnax and Pluvialis apricaria) and were considered here both as "strictly" and "not strictly" protected.

\subsection{Legal contexts}

We categorized Mediterranean countries according to their legal contexts during the time period monitored (Table 1): the older European Union Member States enforcing the Birds Directive and contracting the Bern Convention, hereafter 'BD-BC' (France, Greece, Italy, Spain, Portugal, Fig. 1 in blue), the other contracting parties of the Bern Convention but not enforcing the Birds Directive as they were not Member States to the EU during the study period (two of them joined the EU late during the study period*), hereafter 'BC' (Albania, Bosnia and Herzegovina, Bulgaria*, Croatia, Cyprus*, Macedonia, Montenegro, Morocco, Serbia, Tunisia, Turkey, Fig. 1 in green), and countries that did not ratify the Bern Convention and did not enforce the Birds Directive, hereafter 'No-BD No$\mathrm{BC}^{\prime}$ (Algeria, Israel, Jordan, Lebanon, Libya, Syria, Fig. 1 in grey). 
Between countries, both the number of monitored sites (e.g. Spain vs. Greece, Fig. 1) and the monitoring scheme (Sayoud et al., 2017) vary. Between legal contexts, both the average number of monitored site per year per country and the total number of species were higher in 'BD-BC' (Wilcoxon Mann Whitney, $\mathrm{p}<0.05$, Table S2). The average duration of the monitoring period was shorter in 'No-BD No-BC' (1997-2007 rather than 1991-2012, Table S2).

Table 1: Community Temperature Index trends for waterbirds in the Mediterranean basin from 1991 to 2012 (Significant trends are in bold, alpha <0.05).

\begin{tabular}{|c|c|c|c|c|c|c|}
\hline $\begin{array}{l}\text { Spatial scale \& } \\
\text { Legal context* }\end{array}$ & $\begin{array}{c}\text { Bern } \\
\text { Convention }\end{array}$ & $\begin{array}{c}\text { Birds } \\
\text { Directive }\end{array}$ & $\beta_{\text {year }} \pm$ se & $d f$ & $t$ & $p$ \\
\hline Mediterranean & & & $0.04 \pm 0.00$ & 22935 & 12.97 & $<0.001$ \\
\hline$B D-B C$ & & & $0.04 \pm 0.00$ & 18130 & 11.32 & $<0.001$ \\
\hline France & 1990 & 1979 & $0.02 \pm 0.01$ & 856 & 2.09 & 0.037 \\
\hline Greece & 1983 & 1981 & $0.08 \pm 0.01$ & 1172 & 8.19 & $<0.001$ \\
\hline Italy & 1982 & 1979 & $0.06 \pm 0.01$ & 4644 & 8.34 & $<0.001$ \\
\hline Portugal & 1982 & 1986 & $0.15 \pm 0.02$ & 459 & 7.52 & $<0.001$ \\
\hline Spain & 1986 & 1986 & $0.02 \pm 0.00$ & 10995 & 4.38 & $<0.001$ \\
\hline$B C$ & & & $0.05 \pm 0.01$ & 2976 & 7.97 & $<0.001$ \\
\hline Albania & 1999 & - & $0.02 \pm 0.29$ & 65 & 0.51 & 0.611 \\
\hline Bosnia \& Herz. & 2009 & - & $0.11 \pm 0.19$ & 92 & 0.58 & 0.563 \\
\hline Bulgaria & 1991 & 2007 & $0.09 \pm 0.12$ & 684 & 7.06 & $<0.001$ \\
\hline Croatia & 2000 & - & $0.03 \pm 0.02$ & 133 & 2.34 & 0.021 \\
\hline Cyprus & 1988 & 2004 & $0.12 \pm 0.03$ & 225 & 3.58 & $<0.001$ \\
\hline Macedonia & 1998 & - & $0.02 \pm 0.05$ & 20 & 0.34 & 0.735 \\
\hline Montenegro & 2010 & - & $0.11 \pm 0.10$ & 38 & 1.09 & 0.283 \\
\hline Morocco & 2001 & - & $-0.02 \pm 0.01$ & 851 & -1.22 & 0.223 \\
\hline Serbia & 2008 & - & $0.21 \pm 0.04$ & 33 & 5.18 & $<0.001$ \\
\hline Tunisia & 1996 & - & $0.07 \pm 0.02$ & 482 & 4.34 & $<0.001$ \\
\hline Turkey & 1984 & - & $0.05 \pm 0.01$ & 343 & 3.83 & $<0.001$ \\
\hline No-BD No-BC & & & $-0.01 \pm 0.01$ & 1727 & -0.98 & 0.328 \\
\hline Algeria & - & - & $-0.02 \pm 0.01$ & 1332 & -1.54 & 0.123 \\
\hline Israel & - & - & $0.12 \pm 0.07$ & 219 & 1.75 & 0.082 \\
\hline Jordan & - & - & $0.37 \pm 0.11$ & 65 & 3.29 & 0.002 \\
\hline Lebanon & - & - & $0.68 \pm 0.76$ & 6 & 0.90 & 0.403 \\
\hline Libya & - & - & $-0.07 \pm 0.06$ & 183 & -1.27 & 0.207 \\
\hline Syria & - & - & $-0.28 \pm 0.18$ & 13 & -1.61 & 0.132 \\
\hline
\end{tabular}

* All Mediterranean countries are presented, grouped by legal context, i.e. if and when the country has ratified the Birds Directive and Bern Convention. BD-BC countries that have ratified both before the study period; $B C$ : countries that have ratified the Bern convention at some time before or during the study period; No-BD No-BC: countries that have ratified neither the Birds Directive nor the Bern Convention.

\subsection{Temperature data}

To examine the temperature trend over the two decades, we calculated annual winter temperature anomalies (average monthly temperature across November-December-January, baseline 1990- 
2013) across the whole study area $\left(0.5^{\circ}\right.$ grid resolution). Temperature data were extracted from the HadCRUT4 dataset (Morice et al., 2012).

To account for the strong correlation of CTI with latitude, i.e. the temperature of sites (Temperature proxy), we also calculated a mean winter temperature (Tmean, for November-December-January) for each site across the study period (1990-2013).

\subsection{Data analysis}

\subsubsection{Winter temperature changes}

We assessed the trend in winter average temperature anomalies for each of the three legal contexts 'BD-BC', 'BC' and 'No-BD No-BC' and at the scale of the Mediterranean basin $\left(30^{\circ} \mathrm{N} ; 45^{\circ} \mathrm{N}\right.$ and $10^{\circ} \mathrm{W}$; $40^{\circ} \mathrm{E}$ ) using linear mixed effect models (LMM) with year as a fixed variable and the grid cell identity $\left(0.5^{\circ}\right.$ accuracy) as random effect. A Gaussian correlation structure on geographical coordinates was added to account for spatial autocorrelation.

\subsubsection{Species composition}

Since the EU Member States and the Contracting Parties to the BC are mainly on the northern Mediterranean shore, legal contexts were not randomly distributed in space and species composition was therefore potentially geographically structured. We assessed the differences in species taxonomic and thermic composition between the Mediterranean countries depending on their legal context, for all species and species representing $95 \%$ of the $\log$ (abundance) of the total dataset, i.e. those that contributed the most to CTI. For the two datasets, we assessed the taxonomic differences by a permutation multivariate analysis of variance (PMA, 999 permutations), using a chi-square distance matrix on the species presence/absence per country, and. we used an ANOVA and a Tukey HSD post hoc test to assess the STI differences between each of the three legal contexts.

Because CTI variations are limited by the range of STI values, we checked that the variances of the STI between each legal context were in the same order of magnitude. We then evaluated the difference in relative thermic originality between species protection statuses with a LMM, including species identity as a random factor.

\subsubsection{Community thermic changes}

First, to evaluate the trend in community thermic composition we computed a Community Temperature Index (CTI) for each count event (per site, per year). This CTI is the weighted mean temperature of a community (Devictor et al., 2008) and reflects the thermic affinities of all individuals composing the assemblage. Here it was calculated following Godet et al. (2011), by weighting the STI value of each species by the $\log (x+1)$ of its abundance in the species assemblage divided by the log of total species abundance. A log-transformation was used to account for intraand inter-specific gregarious behaviours (Godet et al., 2011).

Second, we measured the CTI trends and addressed the potential effects of differences in species composition and monitoring on CTI trends between legal contexts. Indeed, the Birds Directive and the Bern Convention have a common European origin (but now BC is extended to the Middle East 
and Maghreb, Fig. 1), challenging the distinction between an effect related to the conservation policies or to an eventual geographic effect.

i) To describe as far as possible the $\mathrm{CTI}$ trend and reduce geographical misinterpretations, we measured the CTI trends at three spatial scales: country $(n=22)$, legal context ('BD-BC', 'BC', 'No-BD No- $B C^{\prime}$ ), and Mediterranean basin ( $\left.n=1\right)$. We assessed the CTI trends per country using LMMs (one model per country) with year (continuous) and $\mathrm{T}_{\text {mean }}$ as fixed effects, and site as a random effect. At the scale of the legal context (one model per legal context) and at the scale of the Mediterranean basin we used LMMs, with year (continuous) and $\mathrm{T}_{\text {mean }}$ as fixed effects, and site nested in country as a random effect to account for the heterogeneity in national monitoring schemes (Sayoud et al., 2017). Because of the monitoring heterogeneity between countries, we also estimated the CTI trend at the Mediterranean scale using a generalised least square model (GLS) on the CTI long-term trend estimates of each country, weighted by their squared standard deviation (weights=1/se2). Spatial autocorrelation was taken into account with an exponential structure, using site geographic coordinates for the models 'country', 'legal context' and 'LMM Mediterranean', and the centroid of monitoring sites in each country for the 'GLS Mediterranean' model.

ii) To account for a potential effect of differences in species composition between legal contexts, we measured the CTI trends using i) all species $(n=145)$ and ii) only those shared by the three legal contexts $(n=108)$.

iii) Finally to assess the effects of the differences in monitoring effort between countries on CTI trends, we tested whether the average number of monitored sites per country per year was correlated to the CTI trend and the CTI standard error (Pearson correlation). We measured the CTI trends using i) the whole monitored period available (1991-2012), and ii) the shorter monitoring period of 'No- BD No-BC' (1997-2007) to account for a potential failure to detect CTI variation due to the monitoring period.

\subsubsection{Protection status and species contributions}

We measured the difference of species contribution to the CTI trend depending on their protection status in each country. These contributions were measured by a leave one out jackknife analysis (Crowley, 1992), removing one by one each species from the dataset to compute CTIs minus one species (Princé and Zuckerberg, 2015). Species contributions were computed as the difference between the estimates of the CTI trend measured in the 'all species model' and the 'model minus a species'. Contributions were then converted to percentages ( 0 to $100 \%$, negative or positive). The sign, positive or negative, of the contribution indicates if the species contributes positively or negatively, respectively, to the overall CTI trend (Davey et al., 2013). Note that in the rare case of a decrease in CTI over time, the sign of the species contribution was inverted in order to always present species contribution in regards of an increasing CTI trend: i.e. if the CTI trend is decreasing, a species contribution presented as $+10 \%$ is in reality $-10 \%$.

The effect of species protection statuses on species contribution was tested using an LMM with the species contributions as the response variable, and the species protection status (strictly vs. not strictly protected), the legal status of the country, and their interaction as fixed effects. Species identity was added as random factor and spatial autocorrelation was taken into account with an exponential structure on the centroid of each country based on sites coordinates. 
To test whether cold-dwelling or warm-dwelling species are driving the increase in CTI, we compared for each legal context and for each protection status the difference in contribution between cold and warm dwelling species. To do so, for each legal context and for each protection status, we used an LMM with the species contribution as the response variable and the relative thermic affinity 'cold' vs. 'warm' as fixed effects. Species identity was added as random factor and spatial autocorrelation was taken into account with an exponential structure on the centroid of each country based on sites coordinates.

We then inferred the relative temporal species trend from their contribution to the CTI trend and their relative thermic originality. Species contribution value (either positive or negative) result from the relative species thermic originality and from the relative species population trend in comparison to the other species in the community. If a warm-dwelling species contributed positively (or negatively) to CTI trend, this species is necessarily increasing (or decreasing) relatively to the other species in the community, and vice versa for the cold-dwelling species (Fig. 3A). We illustrated the relation between the relative species trend and the protection status with a $2 \mathrm{D}$ density plot (species contributing $<0.5 \%$ to the $\mathrm{CTI}$ trend were discarded to facilitate the interpretation, Fig. $3 \mathrm{~B}$ ).

Statistical analyses were performed in R 3.3.0 (R Development Core Team, 2015). LMMs and GLS were run with the package 'nlme' (Pinheiro et al., 2014) and PMA with the package 'vegan' (Oksanen et al., 2013).

\section{Results}

\subsection{Climate warming}

Winter temperatures increased by $0.70{ }^{\circ} \mathrm{C} \pm 0.01 \mathrm{SE}$ during the two decades in the study area (LM, $\beta$ $=0.032 \pm 0.001 \mathrm{SE}, z=46.175, p<0.001)$. The temperature increase was significantly different among the three legal contexts $(p<0.005)$, with ' $B C$ ' $(\beta=0.056 \pm 0.001 \mathrm{SE}, t=38.773, p<0.001)$ higher than 'No- BD No-BC' $(\beta=0.036 \pm 0.001 \mathrm{SE}, t=33.812, p<0.001)$ and higher than 'BD-BC' $(\beta=$ $0.003 \pm 0.001 \mathrm{SE}, \mathrm{t}=2.723, \mathrm{p}=0.007)$.

\subsection{Species composition}

The taxonomic composition of the species assemblages differed among the three legal contexts ( $P M A, F_{1,22}=2.06, p=0.001$ ) and also when considering only species ( 55 species) that represent $95 \%$ of the total abundance (PMA, $F_{1,22}=1.86, p=0.04$ ). However, the assemblages between ' $B C$ ' and 'No-BD No-BC' were not significantly different $\left(P M A, F_{1,17}=1.64, p=0.1\right)$. In average, STI values were significantly different $(p=0.01)$ between 'BD-BC' (mean $=11.40)$ and 'No-BD No- BC' (mean = 14.81) but not between 'BD-BC' vs. 'BC' (mean = 12.65) nor 'No-BD No-BC' vs. 'BC' $(p>0.1)$. No STI differences were detected when considering the most abundant species (i.e. $95 \%$ of the total abundance, $F_{2,168}=0, p=1$ ). The standard deviation of the STI was about the same order of magnitude between the three legal contexts: $\mathrm{SD}_{\mathrm{BD}-\mathrm{BC}}=9.45, \mathrm{SD}_{\mathrm{BC}}=8.76, \mathrm{SD}_{\text {No- } \mathrm{BD} \text { No-BC }}=8.43$. The relative thermic originalities did not differ between species protection $(\mathrm{LMM}, \beta=0.390, \mathrm{SE}=0.228, \mathrm{t}$ $=1.709, \mathrm{p}=0.09$ ).

\subsection{International conservation policy}


CTI significantly increased over time at the Mediterranean scale, with nearly the same values using the GLS model (GLS, $\beta=0.036$, SE $=0.01, t_{1,22}=4.00, p<0.001$ ) or the LMM $(\beta=0.037, p<0.001$, Table 1). In the legal contexts defined by the Birds Directive and/or the Bern Convention contracting parties, 'BD-BC' and 'BC', the CTI significantly increased, while the CTI trend was not significant for no contracting parties 'No-BD No-BC' (Table 1). The results were the same when i) only species shared by the three legal contexts were kept in the analyses, and when ii) the monitoring period was restricted to the shorter monitoring period of the 'No-BD No-BC' legal context (Table S3). At the country scale, the CTI increased in half of the countries all around the Mediterranean basin, including the Middle East and the Maghreb (Portugal, Spain, France, Italy, Croatia, Serbia, Greece, Bulgaria, Turkey, Cyprus, Jordan and Tunisia, Table 1). CTI trends and standard errors were not correlated with the average number of monitored sites annually $\left(r_{\text {Pearson }}=-0.14, p=0.5 ; r_{\text {Pearson }}=\right.$ $-0.23, p=0.3$, respectively). CTI increased significantly in all countries in 'BD-BC', while it did not in four out of the ten ' $\mathrm{BC}$ ' countries which ratified the Bern Convention during (but not before) the study period (Table 1 ).

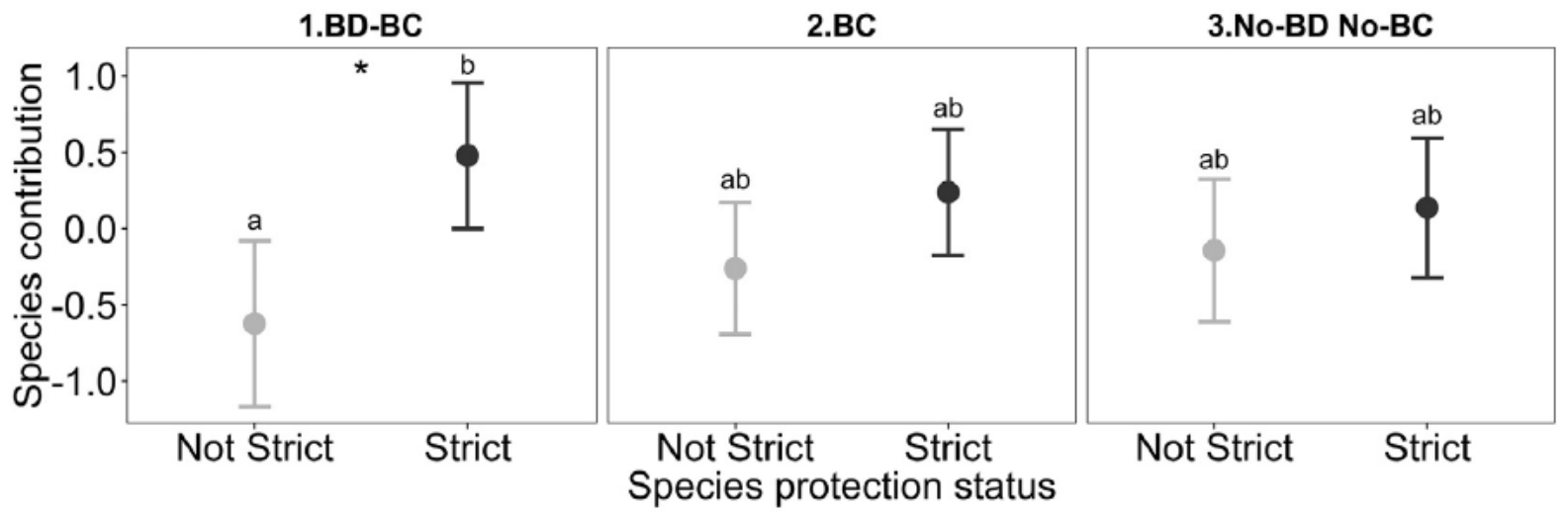

Figure 2: Species contribution to the CTI trend for each protection status (strictly vs. not strictly protected) and under each legal context ('BD-BC', 'BC 'and 'No-BD No-BC'). Significant differences are indicated by different letters and an asterisk “*” (alpha $=0.05)$.

Strictly protected species contributed significantly more to the CTI increase than not strictly protected species inside the BD-BC contracting parties $\left(\beta=1.10, \mathrm{SE}=0.36, \mathrm{t}_{5,3037}=3.04, p=0.03\right.$, Fig. 2 and Fig. 3). However, species protection had no effect on species contributions inside the ' $\mathrm{BC}$ ' Contracting Parties $\left(\beta=0.50, \mathrm{SE}=0.30, \mathrm{t}_{5,3037}=1.70, \mathrm{p}=0.52\right.$, Fig. 2$)$ nor inside the 'No-BD No-BC' countries $\left(\beta=0.28, S E=0.33, t_{5,3037}=0.90, p=0.9\right.$, Fig. 2$)$.

The species contribution to $\mathrm{CTI}$ increase was only significantly related to their relative thermic affinity (cold vs. warm) for the strictly protected species in 'BD-BC' (Table S4, Fig. S1): strictly protected warm-dwelling species in 'BD-BC' contribute more to the CTI increase than strictly protected cold-dwelling species in 'BD-BC' $\left(\beta=0.99, \mathrm{SE}=0.46, \mathrm{t}_{1,327}=2.16, \mathrm{p}=0.03\right.$, Fig. 3, Table S1). Considering the relationships among species contribution, relative species thermic originality and relative species population trend (see methods and Fig. 3), this result means that strictly protected warm-dwelling species in 'BDBC' had a positive population trend relative to the other species. Strictly protected warm-dwelling species which have a positive population trend relatively to the others and which contributed for $>1 \%$ in average to the CTI increase in 'BD-BC' or in 'BC' were Great Egret (Ardea alba), Common Sandpiper (Actitis hypoleucos), Cattle Egret (Bubulcus ibis), White Stork 
(Ciconia ciconia), Little Egret (Egretta garzetta), Blackwinged Stilt (Himantopus himantopus), Great Cormorant (Phalacrocorax carbo), Greater Flamingo (Phoenicopterus roseus), Purple Swamphen (Porphyrio porphyrio) and Green Sandpiper (Tringa ochropus) (Table S1). Not-strictly protected colddwelling species in relative decline, with averaging contribution $>1 \%$ in 'BD-BC' or in 'BC' were Greater White-fronted Goose (Anser albifrons), Mallard (Anas platyrhynchos), Brent Goose (Branta bernicla), Common Goldeneye (Bucephala clangula), Common Coot (Fulica atra), Mew Gull (Larus canus) and Red-breasted Merganser (Mergus serrator) (Table S1).

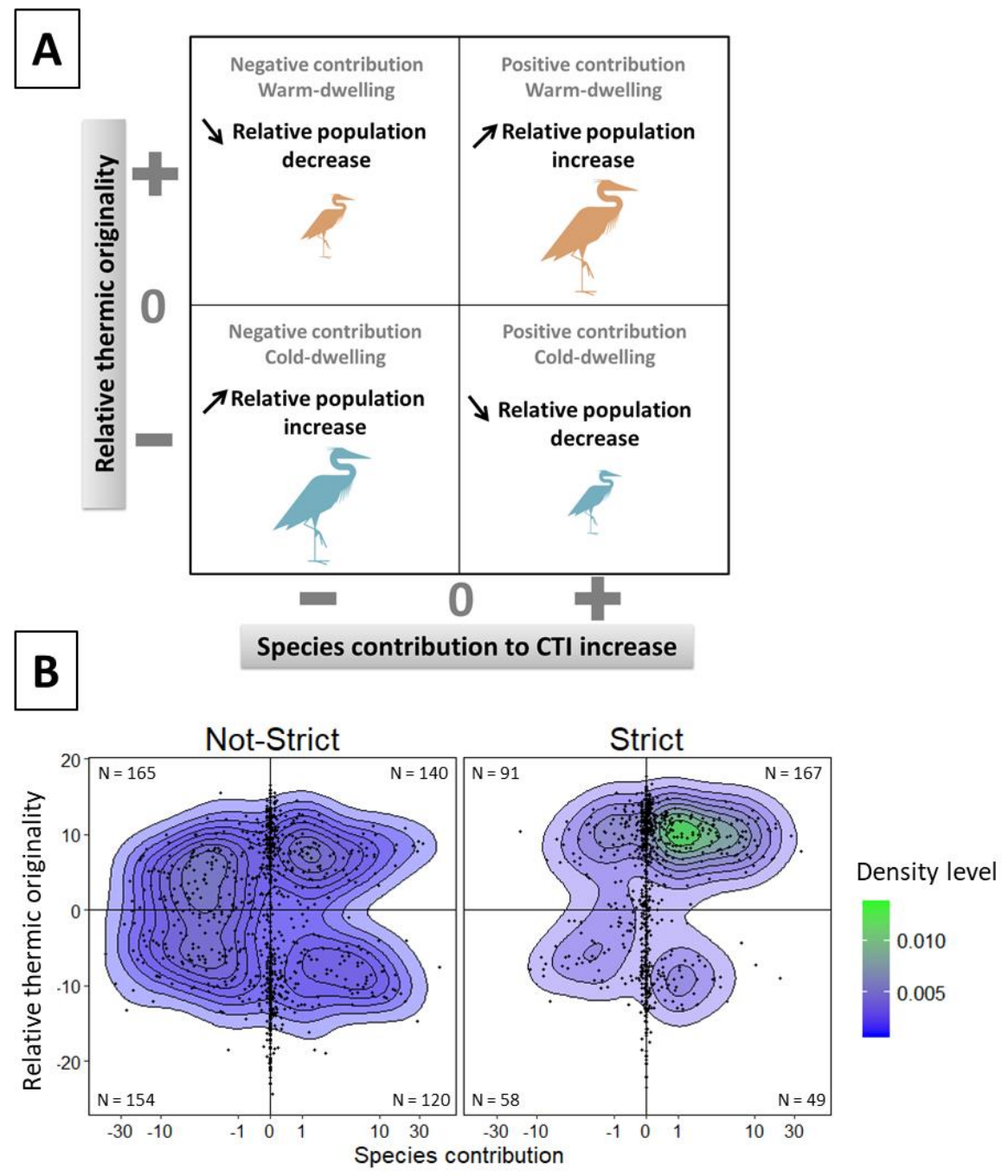

Figure 3: Species contribution to the CTI increase and thermic originality, $(A)$ in a schematic case and (B) in the 'BD-BC' ratifying parties, for the strictly and not strictly protected species. The ' $N$ ' refers to the number of points per quadrant used to determine the density, i.e. species contributing at least at $0.5 \%$ per country. The $X$ axis scale was presented with arcsine transformation to facilitate reading. The division into four quadrants was based in function of the sign (+ or -) of the relative thermic originality and the sign of the species contribution. Thus, each quadrant corresponds to a relative population increase or decrease for warm-dwelling or colddwelling species.

\section{Discussion}


Our study, based on the assessment of changes in community thermic composition of wintering waterbirds in the Mediterranean basin, revealed that community adjustment to climate warming is detected mainly when the two, or one of the two, main Palearctic international conservation policies (the Birds Directive and the Bern Convention) are enforced. In countries where both conservation policies were enforced, strictly protected species, and especially strictly protected warm-dwelling species, have a higher contribution to the CTI increase than not strictly protected species. On the contrary, in 'BC' and 'No-BD No-BC' countries where both conservation policies were not enforced, species mentioned as strictly protected have no higher contributions than species mentioned as not strictly protected. Given the large biological (145 species), temporal (22 years) and spatial (22 countries, 2786 sites) coverage of our study, these results suggest practical implications for conservation.

Our study concerns a large area located at the crossroad of contrasting geopolitical situations challenging detection of community responses to climate warming. A large number of species with varying conservation status are considered, with different distribution range and thermic affinity. They are exposed to various anthropogenic pressures and have experienced different status of protection. Nevertheless, whatever the country and its location, it is expected that communities (and the species within) will have some inherent capacity to respond to climate warming (Parmesan and Yohe, 2003; Chen et al., 2011), particularly for highly mobile animals like wintering waterbirds (Maclean et al., 2008). Thus, we might expect a community thermic increase in response to temperature increase, even in the non-contracting parties mainly situated in Maghreb and Middle East. For example, waterbird communities in the Maghreb include species that currently massively winter in the Sahel (warm-dwelling) like Spatula querquedula, Ardea purpurea or Glareola pratincola, and colder-dwelling species like Larus genei, Anas crecca or Podiceps cristatus. In the context of climate warming, we could expect a CTI increase due to the increase of Sahel wintering species. By determining the CTI trend independently by country we demonstrated that community adjustment was possible in the African (Tunisia) or Middle Eastern countries (Jordan, Turkey).

Maintaining a monitoring effort is one of the main guidelines formulated by Wetland International (Delany, 2005), however monitoring efforts slightly differ between legal contexts, mainly in monitoring period duration and number of sites (Table S2). We showed that the shorter monitoring period in 'No-BD No-BC' should not prevent the detection of a CTI trend (Table S3), and that the number of monitored sites was not correlated with CTI trend or SE. Using the same data, Amano et al. (2018) also found that changes in monitoring effort have little effect in the detection of spatial patterns and estimations of changes in abundances. However, a low spatial coverage of monitoring (number and extent) may reduce the representativeness of CTI trends (e.g. Syria, Fig. 1) and CTI trend for such countries should be taken with caution. As expected, the geographical species distribution in the Mediterranean basin led to differences in species taxonomic and thermic composition. Taxonomic differences seem to have a low impact on CTI change, since ' $\mathrm{BC}$ ' and 'No-BD No-BC' differed in their CTI trends but not in term of the most abundant species (i.e. the species that drive changes in CTI due to the index construction). This suggests that some marginal rare species have restricted distribution ranges, and make a low contribution to the observed patterns due to their low abundance. Moreover, the significant difference in CTI trends between legal contexts was also observed between neighbouring countries, e.g. Tunisia and Algeria, for which species composition is likely very similar. The differences in CTI trends between legal contexts should not be due to a potential limit in possible CTI changes as the range of STI values was similar between legal 
contexts, i.e. CTI can vary with the same magnitude. Strictly protected species in 'BD-BC' contributed more to the $\mathrm{CTI}$ increase even if their relative thermic originalities did not differ from those of the not strictly protected species. These results did not change when using all species or only species shared by the three legal contexts.

Our results provided evidence of a thermic adjustment of waterbird community composition to temperature increase when international conservation policies were enforced. First, an overall community thermic increase was detected where the Birds Directive and/or the Bern Convention were applied. This effect was expected since both these international policies aim to restore, protect, and enhance habitat connectivity as well as to maintain populations in a favorable conservation status (Trouwborst, 2011). As demonstrated by Pavón-Jordán et al. (2015) on the entire flyway of one waterbird species, distribution shift is conditioned by the availability in Special Protection Areas. Indeed, protected area network is needed to ensure resilience of waterbird communities against climate warming (Johnston et al., 2013). Our results are also consistent with those of Gaüzère et al. (2016) who found that in protected areas, including Natura 2000, bird communities better adjust their composition to large temperature variations.

Second, we showed that the community thermic change was mainly driven by strictly protected species. This is observed only in countries where both the Birds Directive and the Bern Convention were applied. These results suggest that strengthening an international convention by national (or here European) legal instrument is more efficient to favour species adaptation to climate change. The observed changes in species assemblages were consistent with the conservation target of these policies: the thermic change resulted mainly from an increase in strictly protected warm-dwelling species rather than a decrease in strictly protected cold-dwelling species (Fig. 3). Among species that were relatively increasing, several benefitted from conservation measures in the past decades (e.g. Greater Flamingo, Johnson, 1997; Little Egret, Tourenq et al., 2000; Great Egret, tawicki, 2014) and experienced a population recovery. For other species which have large wintering populations in subSaharan Africa (e.g. Common Sandpiper, Blackwinged Stilt and Green Sandpiper), their increase in the Mediterranean basin, i.e. northern distribution range, is coherent with the expansion observed for species in their northern boundary (La Sorte and Thompson, 2007; Virkkala and Lehikoinen, 2014). Our results are consistent with previous studies that underlined the negative impact of multiple stressors on adaptation to climate change (Dawson et al., 2011; Gaüzère et al., 2016; Currie and Venne, 2017). Conservation policies, by reducing the exposure of bird populations to multiple anthropogenic stressors - in particular habitat loss and harvesting - increase the capacity of those populations to adjust to climate change. These results support the expectations of the Birds Directive and the Bern Convention to mitigate climate change impact (Trouwborst, 2011) but they also provide evidence of their limited impact for weakly protected species, like legally-hunted species of the BDII. Actually, most of game species were relatively decreasing in the Mediterranean, such as Mallard, White-fronted Goose and Common Coot. Still, outside contracting parties, birds are probably more strongly exposed to stressors (e.g. illegal killing, Brochet et al., 2016) while there are less effective protected areas (Guillemain and Hearn, 2017).

This study provides important insights for policymakers by revealing that climate change adaptation is facilitated when international conservation policies are enforced. Rapid temperature increases are predicted in the Mediterranean over the next decades (Guiot and Cramer, 2016), so it is reassuring to see that species communities can adjust their composition in response to such climate warming 
(Devictor et al., 2012). Since community thermic changes were mainly driven by strictly protected species, we recommend not focusing only on well-studied strictly protected species when assessing the response of species to climate change, which could lead to an over-interpretation of species capacity to track temperature increase. Like other studies (Devictor et al., 2010; Dickinson et al., 2010) we also highlight the important contribution of citizen monitoring programs at a large temporal and spatial scale for biodiversity surveys and the assessment of environmental policies. Because climate change is likely to be the major biodiversity threat of this century, before habitat loss and harvesting (Pereira et al., 2010), progress towards biodiversity conservation objectives might be improved by a reinforcement or a reappraisal of both legal and illegal hunting practices, as well as the continuation of conservation efforts on habitat protection and connectivity (i.e. through the Emerald Network of the Bern Convention or the Natura 2000 network of the Birds and Habitat Directives). Our results suggest that European countries have responsibilities to facilitate the range shift of African wintering waterbird species in response to temperature increase. Finally, these results encourage continued efforts to adopt and enforce international conservation policies, in order to achieve targets of the Convention on Biological Diversity (Campbell et al., 2014).

\section{Acknowledgments}

We acknowledge the thousands of volunteers and professionals involved in waterbird counts, national coordinators from the 23 countries included in the study, the Mediterranean Waterbird Network (Wetlands International, Tour du Valat, the National Office for Hunting and Wildlife, and national IWC North African coordinators GREPOM/ BirdLife Morocco, Directrion Générale des Forêts (Algeria), AAO/ BirdLife Tunisia, Libyan Society for Birds and the Egyptian Environmental Affairs agency) for providing help to national coordinators, centralizing and managing data and making this research possible. We also thank N. Taylor and I. Geijzendorffer for their useful comments and for the improvement of the English and A. Lehikoinen for his valuable comments. Many thanks to K. Princé for her invaluable advices on species contributions. This study was funded by the Foundation Tour du Valat, Foundation Prince Albert II de Monaco, Foundation Total, the French Ministry of "Transition écologique et solidaire" and the MNHN 227 doctoral school. We also thank the editor and the reviewer for their very helpful comments and suggestions. 


\section{Appendix}

Table S1: Species protection status, STI values, contributions and relative thermic originalities

Table S2: Characteristics of the International Waterbird Census between countries and legal contexts

Table S3: CTI trends accounting for species composition and temporal biases.

Table S4: Species contribution of cold vs. warm-dwelling species depending of species protection status.

Figure S1: Species contribution and their thermic originality under two of the legal contexts: 'BC' and 'No-BD No-BC' 
Table S1: Species protection status (Bern Convention and Birds Directive), STI values, species average $( \pm S D)$ contribution to the CTI increase (\%) and relative thermic originality (average) per legal contexts (BD-BC countries that have ratified both policies before the study period; BC: countries that have ratified the Bern convention before or during the study period; No BC-No BD: countries that have ratified neither the Bern Convention nor the Birds Directive). Species relatively increasing are highlighted in grey.

\begin{tabular}{|c|c|c|c|c|c|c|c|c|c|}
\hline \multirow[b]{2}{*}{ Scientific name } & \multicolumn{2}{|c|}{$B D-B C$} & \multicolumn{2}{|l|}{$\mathrm{BC}$} & \multicolumn{2}{|c|}{ No-BD No-BC } & \multirow[b]{2}{*}{ STI } & \multirow[b]{2}{*}{ Bern } & \multirow[b]{2}{*}{ BD } \\
\hline & $\begin{array}{c}\text { Average } \\
\text { contribution }\end{array}$ & $\begin{array}{c}\text { Relative } \\
\text { thermic } \\
\text { originality }\end{array}$ & $\begin{array}{c}\text { Average } \\
\text { contribution }\end{array}$ & $\begin{array}{c}\text { Relative } \\
\text { thermic } \\
\text { originality }\end{array}$ & $\begin{array}{c}\text { Average } \\
\text { contribution }\end{array}$ & $\begin{array}{l}\text { Relative } \\
\text { thermic } \\
\text { originality }\end{array}$ & & & \\
\hline Actitis hypoleucos & $3.43 \pm 4.24$ & 11.34 & $0.90 \pm 2.15$ & 12.58 & $2.39 \pm 4.02$ & 10.44 & 23.16 & Bern-II & - \\
\hline Alca torda & $-0.19 \pm 0.25$ & -10.37 & $0.00 \pm 0.05$ & -9.13 & $0.00 \pm 0.01$ & -11.26 & 1.45 & Bern-III & - \\
\hline Alle alle & $0.00 \pm 0.00$ & -18.45 & $0.00 \pm 0.05$ & -17.21 & $0.00 \pm 0.01$ & -19.34 & -6.63 & Bern-III & - \\
\hline Anas acuta & $-5.23 \pm 4.05$ & 5.08 & $-2.08 \pm 3.06$ & 6.32 & $-0.72 \pm 3.26$ & 4.18 & 16.90 & Bern-III & BD-II \\
\hline Anas crecca & $-12.45 \pm 11.73$ & 0.91 & $-3.03 \pm 3.98$ & 2.14 & $-5.28 \pm 8.56$ & 0.01 & 12.72 & Bern-III & BD-II \\
\hline Anas platyrhynchos & $6.09 \pm 18.01$ & -11.84 & $6.13 \pm 23.95$ & -10.60 & $-3.21 \pm 25.04$ & -12.73 & -0.02 & Bern-III & BD-II \\
\hline Anser albifrons & $0.12 \pm 0.58$ & -9.28 & $1.60 \pm 3.66$ & -8.05 & $2.93 \pm 9.08$ & -10.18 & 2.53 & Bern-III & BD-I \\
\hline Anser anser & $-0.63 \pm 2.87$ & -7.35 & $0.83 \pm 2.35$ & -6.12 & $1.95 \pm 3.65$ & -8.25 & 4.47 & Bern-III & BD-II \\
\hline Anser brachyrhynchus & $-0.01 \pm 0.03$ & -9.80 & $0.00 \pm 0.05$ & -8.56 & $0.00 \pm 0.01$ & -10.69 & 2.02 & Bern-III & BD-II \\
\hline Anser erythropus & $-0.04 \pm 0.09$ & -9.38 & $0.00 \pm 0.04$ & -8.15 & $0.00 \pm 0.01$ & -10.28 & 2.43 & Bern-II & BD-I \\
\hline Anser fabalis & $0.16 \pm 0.15$ & -14.33 & $0.03 \pm 0.27$ & -13.10 & $0.00 \pm 0.01$ & -15.23 & -2.51 & Bern-III & BD-II \\
\hline Ardea alba & $9.88 \pm 6.27$ & 10.04 & $4.30 \pm 4.13$ & 11.27 & $4.15 \pm 4.12$ & 9.14 & 21.86 & Bern-II & BD-I \\
\hline Ardea cinerea & $-3.54 \pm 8.87$ & 6.92 & $7.33 \pm 8.14$ & 8.15 & $8.54 \pm 11.38$ & 6.02 & 18.73 & Bern-III & - \\
\hline Ardea purpurea & $0.05 \pm 0.19$ & 12.05 & $0.08 \pm 0.24$ & 13.29 & $-0.46 \pm 1.33$ & 11.16 & 23.87 & Bern-II & BD-I \\
\hline Ardeola ralloides & $0.03 \pm 0.05$ & 11.97 & $0.01 \pm 0.06$ & 13.21 & $0.43 \pm 0.60$ & 11.08 & 23.79 & Bern-II & BD-I \\
\hline Arenaria interpres & $0.52 \pm 0.46$ & 6.04 & $0.08 \pm 0.22$ & 7.28 & $-0.09 \pm 0.27$ & 5.15 & 17.86 & Bern-II & - \\
\hline Aythya ferina & $-6.22 \pm 1.84$ & -0.48 & $-5.97 \pm 7.92$ & 0.76 & $-1.16 \pm 3.86$ & -1.38 & 11.34 & Bern-III & BD-II \\
\hline Aythya fuligula & $-1.37 \pm 0.66$ & -1.37 & $-4.06 \pm 7.14$ & -0.13 & $0.20 \pm 1.26$ & -2.26 & 10.45 & Bern-III & BD-II \\
\hline Aythya marila & $0.03 \pm 0.06$ & -11.39 & $0.57 \pm 1.52$ & -10.15 & $-0.10 \pm 0.25$ & -12.28 & 0.43 & Bern-III & BD-II \\
\hline Aythya nyroca & $-0.36 \pm 0.39$ & -2.04 & $-0.29 \pm 1.08$ & -0.81 & $-0.61 \pm 0.98$ & -2.94 & 9.77 & Bern-III & BD-I \\
\hline Botaurus stellaris & $0.00 \pm 0.27$ & 6.58 & $0.05 \pm 0.42$ & 7.81 & $0.05 \pm 0.17$ & 5.68 & 18.39 & Bern-II & BD-I \\
\hline Branta bernicla & $2.24 \pm 4.79$ & -8.95 & $0.00 \pm 0.05$ & -7.72 & $0.00 \pm 0.01$ & -9.85 & 2.86 & Bern-III & BD-II \\
\hline Branta leucopsis & $-0.03 \pm 0.23$ & -10.13 & $0.00 \pm 0.05$ & -8.90 & $0.00 \pm 0.01$ & -11.03 & 1.69 & Bern-II & BD-I \\
\hline Branta ruficollis & $-0.02 \pm 0.05$ & -10.72 & $0.02 \pm 0.17$ & -9.48 & $0.00 \pm 0.01$ & -11.61 & 1.10 & Bern-II & BD-I \\
\hline Bubulcus ibis & $6.27 \pm 6.80$ & 11.14 & $1.56 \pm 2.50$ & 12.38 & $2.34 \pm 7.97$ & 10.25 & 22.96 & Bern-II & - \\
\hline Bucephala clangula & $0.55 \pm 0.50$ & -12.92 & $2.54 \pm 6.51$ & -11.69 & $1.54 \pm 3.96$ & -13.82 & -1.11 & Bern-III & BD-II \\
\hline Calidris alba & $0.36 \pm 0.39$ & 7.04 & $-0.16 \pm 0.43$ & 8.28 & $-0.32 \pm 0.98$ & 6.15 & 18.86 & Bern-II & - \\
\hline Calidris alpina & $0.09 \pm 0.89$ & 0.01 & $-0.56 \pm 1.35$ & 1.25 & $-3.07 \pm 4.87$ & -0.88 & 11.83 & Bern-II & - \\
\hline Calidris canutus & $-0.01 \pm 0.07$ & 7.26 & $0.00 \pm 0.06$ & 8.50 & $-0.11 \pm 0.25$ & 6.37 & 19.08 & Bern-III & BD-II \\
\hline Calidris falcinellus & $0.00 \pm 0.00$ & 11.86 & $0.01 \pm 0.05$ & 13.09 & $0.00 \pm 0.01$ & 10.96 & 23.68 & Bern-II & - \\
\hline Calidris ferruginea & $0.16 \pm 0.29$ & 11.61 & $0.15 \pm 0.36$ & 12.85 & $-0.17 \pm 1.49$ & 10.72 & 23.43 & Bern-II & - \\
\hline Calidris maritima & $0.19 \pm 0.57$ & -14.30 & $0.00 \pm 0.05$ & -13.06 & $0.00 \pm 0.01$ & -15.20 & -2.48 & Bern-II & - \\
\hline Calidris minuta & $-1.08 \pm 2.18$ & 10.96 & $1.96 \pm 3.94$ & 12.19 & $1.93 \pm 3.05$ & 10.06 & 22.77 & Bern-II & - \\
\hline Calidris pugnax & $0.11 \pm 0.29$ & 11.15 & $-0.37 \pm 0.78$ & 12.38 & $0.69 \pm 3.22$ & 10.25 & 22.96 & Bern-III & BD-I \\
\hline Calidris temminckii & $0.04 \pm 0.10$ & 11.50 & $-0.06 \pm 0.19$ & 12.74 & $0.13 \pm 0.66$ & 10.61 & 23.32 & Bern-II & - \\
\hline Catharacta skua & $0.00 \pm 0.01$ & -11.69 & $0.00 \pm 0.05$ & -10.46 & $-0.09 \pm 0.25$ & -12.59 & 0.12 & Bern-III & - \\
\hline Charadrius alexandrinus & $0.47 \pm 0.68$ & 7.38 & $0.95 \pm 3.36$ & 8.62 & $0.93 \pm 6.51$ & 6.49 & 19.20 & Bern-II & - \\
\hline
\end{tabular}




\begin{tabular}{|c|c|c|c|c|c|c|c|c|c|}
\hline & & & & & & & & & \\
\hline Charadrius dubius & $0.03 \pm 0.30$ & 11.98 & $0.22 \pm 0.81$ & 13.22 & $0.60 \pm 1.23$ & 11.09 & 23.80 & Bern-II & - \\
\hline Charadrius hiaticula & $-0.08 \pm 0.26$ & 10.29 & $-0.06 \pm 0.27$ & 11.53 & $1.03 \pm 4.02$ & 9.40 & 22.11 & Bern-II & - \\
\hline Charadrius leschenaultii & $0.01 \pm 0.02$ & 9.74 & $0.17 \pm 0.53$ & 10.98 & $-0.13 \pm 0.20$ & 8.85 & 21.56 & Bern-II & - \\
\hline Chlidonias hybrida & $0.16 \pm 0.32$ & 9.83 & $0.30 \pm 0.90$ & 11.07 & $-0.3 .0 \pm 0.77$ & 8.94 & 21.65 & Bern-II & BD-I \\
\hline Chlidonias leucopterus & $0.00 \pm 0.00$ & 10.80 & $0.01 \pm 0.05$ & 12.04 & $-0.02 \pm 0.04$ & 9.91 & 22.62 & Bern-II & - \\
\hline Chlidonias niger & $-0.01 \pm 0.02$ & 10.80 & $-0.03 \pm 0.15$ & 12.04 & $0.08 \pm 0.14$ & 9.91 & 22.62 & Bern-II & BD-I \\
\hline Ciconia ciconia & $3.92 \pm 3.83$ & 11.13 & $0.22 \pm 0.42$ & 12.37 & $-0.03 \pm 2.86$ & 10.24 & 22.95 & Bern-II & BD-I \\
\hline Ciconia nigra & $0.07 \pm 0.14$ & 11.17 & $-0.07 \pm 0.35$ & 12.40 & $0.41 \pm 1.16$ & 10.27 & 22.98 & Bern-II & BD-I \\
\hline Clangula hyemalis & $0.07 \pm 0.05$ & -14.32 & $0.12 \pm 0.25$ & -13.08 & $0.00 \pm 0.01$ & -15.21 & -2.50 & Bern-III & BD-II \\
\hline Crex crex & $0.00 \pm 0.00$ & 11.64 & $0.00 \pm 0.05$ & 12.88 & $-0.33 \pm 0.86$ & 10.75 & 23.46 & Bern-III & BD-I \\
\hline Cygnus columbianus & $-0.16 \pm 0.3$ & -9.38 & $-0.18 \pm 0.54$ & -8.14 & $-0.02 \pm 0.04$ & -10.28 & 2.44 & Bern-II & BD-I \\
\hline Cygnus cygnus & $0.25 \pm 0.41$ & -13.31 & $0.33 \pm 0.48$ & -12.07 & $0.00 \pm 0.01$ & -14.20 & -1.49 & Bern-II & BD-I \\
\hline Cygnus olor & $-0.78 \pm 4.99$ & -10.55 & $-0.99 \pm 3.02$ & -9.31 & $0.85 \pm 2.07$ & -11.44 & 1.27 & Bern-III & BD-II \\
\hline Egretta garzetta & $4.42 \pm 2.55$ & 9.45 & $2.30 \pm 4.77$ & 10.68 & $-0.06 \pm 0.44$ & 8.55 & 21.26 & Bern-II & BD-I \\
\hline Egretta gularis & $0.00 \pm 0.00$ & 11.62 & $-0.02 \pm 0.09$ & 12.86 & $0.42 \pm 1.13$ & 10.73 & 23.44 & Bern-III & BD-I \\
\hline Fratercula arctica & $0.00 \pm 0.00$ & -16.81 & $0.00 \pm 0.05$ & -15.57 & $0.00 \pm 0.01$ & -17.70 & -4.99 & Bern-III & - \\
\hline Fulica atra & $3.88 \pm 3.43$ & -5.95 & $-7.86 \pm 18.79$ & -4.72 & $-3.36 \pm 11.94$ & -6.85 & 5.86 & Bern-III & BD-II \\
\hline Fulica cristata & $0.05 \pm 0.11$ & 10.77 & $-0.57 \pm 1.80$ & 12.01 & $0.00 \pm 0.01$ & 9.88 & 22.59 & Bern-II & BD-I \\
\hline Gallinago gallinago & $-1.06 \pm 2.26$ & 6.77 & $-0.40 \pm 2.10$ & 8.00 & $-3.62 \pm 4.81$ & 5.87 & 18.58 & Bern-III & BD-II \\
\hline Gallinago media & $-0.01 \pm 0.03$ & 12.05 & $-0.02 \pm 0.05$ & 13.29 & $-0.40 \pm 1.09$ & 11.16 & 23.87 & Bern-II & BD-I \\
\hline Gallinula chloropus & $3.1 \pm 3.26$ & 4.49 & $0.88 \pm 2.03$ & 5.73 & $1.75 \pm 3.21$ & 3.59 & 16.31 & Bern-III & BD-II \\
\hline Gavia arctica & $0.36 \pm 0.38$ & -11.05 & $-1.10 \pm 2.70$ & -9.82 & $0.79 \pm 2.09$ & -11.95 & 0.76 & Bern-II & BD-I \\
\hline Gavia immer & $0.42 \pm 0.76$ & -11.86 & $0.00 \pm 0.05$ & -10.62 & $0.00 \pm 0.01$ & -12.76 & -0.04 & Bern-II & BD-I \\
\hline Gavia stellata & $0.17 \pm 0.17$ & -8.76 & $0.11 \pm 0.34$ & -7.53 & $-0.83 \pm 2.18$ & -9.66 & 3.05 & Bern-II & BD-I \\
\hline Gelochelidon nilotica & $0.01 \pm 0.01$ & 10.20 & $-0.01 \pm 0.07$ & 11.44 & $-0.05 \pm 0.11$ & 9.31 & 22.02 & Bern-II & BD-I \\
\hline Glareola pratincola & $0.00 \pm 0.00$ & 12.17 & $-0.01 \pm 0.05$ & 13.41 & $0.00 \pm 0.01$ & 11.27 & 23.99 & Bern-II & BD-I \\
\hline Grus grus & $0.5 \pm 1.35$ & 2.90 & $0.51 \pm 2.62$ & 4.13 & $0.10 \pm 1.41$ & 2.00 & 14.72 & Bern-II & BD-I \\
\hline Haematopus ostralegus & $-0.07 \pm 0.14$ & 3.52 & $-0.04 \pm 0.18$ & 4.76 & $0.05 \pm 0.17$ & 2.63 & 15.34 & Bern-III & BD-II \\
\hline Himantopus himantopus & $1.87 \pm 2.5$ & 10.31 & $-0.57 \pm 2.72$ & 11.54 & $3.49 \pm 9.14$ & 9.41 & 22.13 & Bern-III & BD-I \\
\hline Hydroprogne caspia & $0.06 \pm 0.07$ & 9.59 & $-0.13 \pm 0.45$ & 10.82 & $0.11 \pm 0.29$ & 8.69 & 21.40 & Bern-II & BD-I \\
\hline Ixobrychus minutus & $0.11 \pm 0.18$ & 12.19 & $0.00 \pm 0.05$ & 13.43 & $-0.24 \pm 0.60$ & 11.30 & 24.01 & Bern-II & BD-I \\
\hline Larus argentatus & $-9.96 \pm 7.85$ & -7.24 & $-7.74 \pm 10.31$ & -6.00 & $-0.41 \pm 8.94$ & -8.13 & 4.58 & Bern-III & BD-II \\
\hline Larus audouinii & $-0.01 \pm 0.07$ & -0.36 & $0.13 \pm 0.46$ & 0.87 & $0.16 \pm 0.57$ & -1.26 & 11.45 & Bern-II & BD-I \\
\hline Larus canus & $-0.43 \pm 1.07$ & -10.20 & $1.15 \pm 2.91$ & -8.96 & $0.88 \pm 2.71$ & -11.09 & 1.62 & Bern-III & BD-II \\
\hline Larus fuscus & $0.22 \pm 0.43$ & 6.76 & $0.00 \pm 0.05$ & 8.00 & $-0.80 \pm 2.11$ & 5.87 & 18.58 & Bern-III & BD-II \\
\hline Larus genei & $-0.29 \pm 0.45$ & 0.08 & $-0.32 \pm 1.12$ & 1.32 & $1.03 \pm 1.84$ & -0.81 & 11.90 & Bern-II & BD-I \\
\hline Larus glaucoides & $0.00 \pm 0.01$ & -13.45 & $0.00 \pm 0.05$ & -12.22 & $0.00 \pm 0.01$ & -14.35 & -1.63 & Bern-III & - \\
\hline Larus hemprichii & $0.00 \pm 0.00$ & 11.69 & $0.07 \pm 0.22$ & 12.92 & $0.01 \pm 0.05$ & 10.79 & 23.50 & Bern-III & - \\
\hline Larus hyperboreus & $0.00 \pm 0.03$ & -21.48 & $0.00 \pm 0.05$ & -20.24 & $0.00 \pm 0.01$ & -22.37 & -9.66 & Bern-III & - \\
\hline Larus ichthyaetus & $0.00 \pm 0.01$ & -0.10 & $0.08 \pm 0.26$ & 1.13 & $-0.31 \pm 1.09$ & -1.00 & 11.71 & Bern-III & - \\
\hline Larus leucophthalmus & $0.00 \pm 0.00$ & 10.84 & $0.00 \pm 0.05$ & 12.08 & $-0.29 \pm 0.76$ & 9.95 & 22.66 & Bern-III & - \\
\hline Larus marinus & $-0.31 \pm 0.78$ & -14.31 & $0.04 \pm 0.11$ & -13.07 & $-0.06 \pm 0.10$ & -15.20 & -2.49 & Bern-III & BD-II \\
\hline Larus melanocephalus & $-0.61 \pm 0.42$ & -2.51 & $-0.22 \pm 0.66$ & -1.28 & $0.08 \pm 2.16$ & -3.41 & 9.31 & Bern-II & BD-I \\
\hline Larus ridibundus & $0.76 \pm 7.14$ & -5.24 & $-5.56 \pm 6.53$ & -4.00 & $1.78 \pm 3.37$ & -6.13 & 6.58 & Bern-III & BD-II \\
\hline Limosa lapponica & $-0.06 \pm 0.34$ & 7.41 & $-0.02 \pm 0.11$ & 8.65 & $0.11 \pm 0.17$ & 6.51 & 19.23 & Bern-III & BD-II \\
\hline Limosa limosa & $-0.48 \pm 0.98$ & 9.20 & $-0.52 \pm 3.26$ & 10.43 & $-0.38 \pm 1.25$ & 8.30 & 21.01 & Bern-III & BD-II \\
\hline Lymnocryptes minimus & $-0.02 \pm 0.10$ & 8.21 & $-0.01 \pm 0.16$ & 9.45 & $0.08 \pm 0.24$ & 7.32 & 20.03 & Bern-III & BD-II \\
\hline Mareca penelope & $-8.85 \pm 3.05$ & 4.71 & $-4.04 \pm 10.94$ & 5.95 & $-2.77 \pm 7.22$ & 3.82 & 16.53 & Bern-III & BD-II \\
\hline
\end{tabular}




\begin{tabular}{|c|c|c|c|c|c|c|c|c|c|}
\hline \multirow{3}{*}{ Mareca strepera } & & & & & & & & & \\
\hline & $-2.64 \pm 3.89$ & -0.08 & \multirow[t]{2}{*}{$0.10 \pm 0.85$} & \multirow[t]{2}{*}{1.15} & $0.30 \pm 1.16$ & -0.98 & 11.73 & Bern-III & BD-II \\
\hline & & & & & & & & & \\
\hline angustirostris & $0.01 \pm 0.03$ & -5.86 & $-0.31 \pm 1.69$ & -4.63 & $-0.73 \pm 1.44$ & -6.76 & 5.95 & Bern-II & BD-I \\
\hline Melanitta fusca & $0.12 \pm 0.20$ & -11.15 & $-0.43 \pm 1.46$ & -9.91 & $0.00 \pm 0.01$ & -12.04 & 0.67 & Bern-III & BD-II \\
\hline Melanitta nigra & $0.06 \pm 0.44$ & -9.54 & $0.00 \pm 0.21$ & -8.30 & $0.00 \pm 0.01$ & -10.43 & 2.28 & Bern-III & BD-II \\
\hline Mergellus albellus & $0.07 \pm 0.10$ & -13.40 & $1.36 \pm 1.83$ & -12.16 & $-1.27 \pm 2.35$ & -14.29 & -1.58 & Bern-II & - \\
\hline Mergus merganser & $-0.06 \pm 0.35$ & -12.21 & $-0.51 \pm 1.56$ & -10.98 & $-0.28 \pm 0.70$ & -13.11 & -0.40 & Bern-III & BD-II \\
\hline Mergus serrator & $1.23 \pm 2.12$ & -12.90 & $0.28 \pm 5.46$ & -11.66 & $-0.08 \pm 0.49$ & -13.80 & -1.08 & Bern-III & BD-II \\
\hline Microcarbo pygmaeus & $-1.75 \pm 3.69$ & -9.07 & $-3.13 \pm 4.29$ & -7.84 & $-0.37 \pm 1.52$ & -9.97 & 2.74 & Bern-II & BD-I \\
\hline Morus bassanus & $-0.57 \pm 0.90$ & -11.28 & $0.08 \pm 0.28$ & -10.05 & $-0.16 \pm 0.43$ & -12.18 & 0.54 & Bern-III & - \\
\hline Netta rufina & $0.78 \pm 2.23$ & -6.46 & $0.98 \pm 1.44$ & -5.23 & $-0.43 \pm 1.40$ & -7.36 & 5.35 & Bern-III & BD-II \\
\hline Numenius arquata & $-0.75 \pm 1.30$ & 7.07 & $-0.05 \pm 1.37$ & 8.31 & $-0.66 \pm 2.75$ & 6.18 & 18.89 & Bern-III & BD-II \\
\hline Numenius phaeopus & $0.29 \pm 0.28$ & 10.24 & $-0.01 \pm 0.13$ & 11.48 & $0.02 \pm 0.07$ & 9.35 & 22.06 & Bern-III & BD-II \\
\hline Numenius tenuirostris & $0.00 \pm 0.00$ & -1.36 & $-0.04 \pm 0.14$ & -0.13 & $0.00 \pm 0.02$ & -2.26 & 10.45 & Bern-II & BD-I \\
\hline Nycticorax nycticorax & $0.18 \pm 0.87$ & 11.65 & $0.09 \pm 0.26$ & 12.89 & $-0.12 \pm 0.98$ & 10.76 & 23.47 & Bern-II & BD-I \\
\hline Oxyura leucocephala & $-0.21 \pm 0.75$ & -10.55 & $-0.31 \pm 2.48$ & -9.31 & $-3.47 \pm 6.20$ & -11.44 & 1.27 & Bern-II & BD-I \\
\hline Pelecanus crispus & $-0.57 \pm 1.28$ & -3.45 & $0.10 \pm 0.42$ & -2.22 & $0.05 \pm 0.07$ & -4.35 & 8.37 & Bern-III & BD-I \\
\hline Pelecanus onocrotalus & $-0.04 \pm 0.11$ & 10.19 & $0.08 \pm 0.22$ & 11.42 & $-0.74 \pm 1.55$ & 9.29 & 22.01 & Bern-III & BD-I \\
\hline Phalacrocorax carbo & $12.74 \pm 13.42$ & 6.59 & $14.59 \pm 15.47$ & 7.83 & $2.98 \pm 8.80$ & 5.70 & 18.41 & Bern-III & BD-I \\
\hline Phalaropus fulicarius & $0.00 \pm 0.01$ & 8.17 & $0.00 \pm 0.05$ & 9.40 & $0.00 \pm 0.01$ & 7.27 & 19.99 & Bern-II & - \\
\hline Phalaropus lobatus & $0.00 \pm 0.00$ & 10.99 & $0.03 \pm 0.10$ & 12.23 & $-0.01 \pm 0.02$ & 10.09 & 22.81 & Bern-II & BD-I \\
\hline Phoeniconaias minor & $0.01 \pm 0.01$ & 11.11 & $0.00 \pm 0.06$ & 12.35 & $0.00 \pm 0.01$ & 10.21 & 22.93 & Bern-III & - \\
\hline Phoenicopterus roseus & $2.71 \pm 4.25$ & 8.77 & $-0.90 \pm 5.77$ & 10.00 & $-4.43 \pm 6.73$ & 7.87 & 20.58 & Bern-III & BD-I \\
\hline Platalea leucorodia & $0.71 \pm 0.43$ & 6.13 & $-0.14 \pm 1.06$ & 7.37 & $0.26 \pm 0.33$ & 5.24 & 17.95 & Bern-III & BD-I \\
\hline Plegadis falcinellus & $0.41 \pm 0.49$ & 11.32 & $-0.35 \pm 1.25$ & 12.56 & $0.71 \pm 1.02$ & 10.42 & 23.14 & Bern-III & BD-I \\
\hline Pluvialis apricaria & $-2.15 \pm 1.16$ & -6.46 & $-1.06 \pm 1.65$ & -5.22 & $-1.82 \pm 4.01$ & -7.36 & 5.36 & Bern-III & BD-I \\
\hline Pluvialis squatarola & $0.12 \pm 0.72$ & 7.02 & $0.73 \pm 1.86$ & 8.26 & $0.26 \pm 1.66$ & 6.12 & 18.84 & Bern-III & BD-II \\
\hline Podiceps auritus & $-0.04 \pm 0.04$ & -8.42 & $0.15 \pm 0.35$ & -7.19 & $0.09 \pm 0.29$ & -9.32 & 3.39 & Bern-II & BD-I \\
\hline Podiceps cristatus & $-2.16 \pm 3.91$ & -1.73 & $-2.45 \pm 3.46$ & -0.50 & $-0.25 \pm 2.28$ & -2.63 & 10.08 & Bern-III & - \\
\hline Podiceps grisegena & $0.29 \pm 0.27$ & -9.54 & $0.41 \pm 0.77$ & -8.31 & $-0.05 \pm 0.10$ & -10.44 & 2.27 & Bern-II & - \\
\hline Podiceps nigricollis & $-2.66 \pm 3.24$ & 6.18 & $-0.76 \pm 3.20$ & 7.42 & $2.77 \pm 4.13$ & 5.29 & 18.00 & Bern-II & - \\
\hline Porphyrio alleni & $0.00 \pm 0.00$ & 12.33 & $-0.01 \pm 0.06$ & 13.57 & $0.00 \pm 0.01$ & 11.44 & 24.15 & Bern-III & - \\
\hline Porphyrio porphyrio & $1.36 \pm 2.00$ & 10.30 & $-0.03 \pm 0.62$ & 11.54 & $0.38 \pm 0.89$ & 9.41 & 22.12 & Bern-II & BD-I \\
\hline Rallus aquaticus & $-1.75 \pm 1.95$ & -7.29 & $-0.55 \pm 1.54$ & -6.06 & $0.74 \pm 2.33$ & -8.19 & 4.52 & Bern-III & BD-II \\
\hline Recurvirostra avosetta & $-1.57 \pm 1.56$ & 10.23 & $-0.06 \pm 1.73$ & 11.46 & $-0.89 \pm 3.02$ & 9.33 & 22.04 & Bern-II & BD-I \\
\hline Rissa tridactyla & $-0.02 \pm 0.05$ & -7.02 & $0.01 \pm 0.05$ & -5.78 & $0.00 \pm 0.01$ & -7.91 & 4.80 & Bern-III & - \\
\hline Somateria mollissima & $0.80 \pm 0.98$ & -19.35 & $-0.01 \pm 0.65$ & -18.11 & $0.00 \pm 0.01$ & -20.24 & -7.53 & Bern-III & BD-II \\
\hline Somateria spectabilis & $0.00 \pm 0.00$ & -20.61 & $0.00 \pm 0.05$ & -19.38 & $0.00 \pm 0.01$ & -21.51 & -8.79 & Bern-II & - \\
\hline Spatula clypeata & $-6.73 \pm 6.92$ & 3.09 & $-0.08 \pm 2.34$ & 4.33 & $-2.31 \pm 4.71$ & 2.20 & 14.91 & Bern-III & BD-II \\
\hline Spatula querquedula & $0.06 \pm 0.07$ & 11.25 & $-0.36 \pm 0.88$ & 12.48 & $0.12 \pm 1.36$ & 10.35 & 23.07 & Bern-III & BD-II \\
\hline Sterna hirundo & $-0.01 \pm 0.15$ & 13.43 & $-0.02 \pm 0.11$ & 14.67 & $0.00 \pm 0.95$ & 12.54 & 25.25 & Bern-II & BD-I \\
\hline Sterna paradisaea & $0.00 \pm 0.00$ & -3.90 & $0.01 \pm 0.05$ & -2.66 & $0.00 \pm 0.01$ & -4.79 & 7.92 & Bern-II & BD-I \\
\hline Sternula albifrons & $0.00 \pm 0.00$ & 3.89 & $0.00 \pm 0.05$ & 5.13 & $0.00 \pm 0.02$ & 3.00 & 15.71 & Bern-II & BD-I \\
\hline Tachybaptus ruficollis & $1.78 \pm 4.87$ & 6.78 & $4.94 \pm 4.97$ & 8.02 & $0.42 \pm 9.76$ & 5.88 & 18.60 & Bern-III & - \\
\hline Tadorna ferruginea & $-0.02 \pm 0.08$ & -2.94 & $0.26 \pm 2.45$ & -1.70 & $-0.77 \pm 2.81$ & -3.83 & 8.88 & Bern-II & BD-I \\
\hline Tadorna tadorna & $-1.33 \pm 1.97$ & -7.52 & $2.24 \pm 7.94$ & -6.28 & $2.25 \pm 7.81$ & -8.41 & 4.30 & Bern-II & - \\
\hline Thalasseus bengalensis & $0.00 \pm 0.00$ & 9.94 & $0.00 \pm 0.05$ & 11.17 & $0.11 \pm 0.22$ & 9.04 & 21.76 & Bern-III & - \\
\hline Thalasseus sandvicensis & $-0.18 \pm 0.48$ & 0.56 & $-0.12 \pm 0.27$ & 1.80 & $-0.04 \pm 0.08$ & -0.33 & 12.38 & Bern-II & BD-I \\
\hline
\end{tabular}




\begin{tabular}{|c|c|c|c|c|c|c|c|c|c|}
\hline Tringa erythropus & $0.12 \pm 0.37$ & 9.22 & $-0.12 \pm 0.83$ & 10.45 & $-0.44 \pm 1.11$ & 8.32 & 21.03 & Bern-III & BD-II \\
\hline Tringa glareola & $0.12 \pm 0.18$ & 11.71 & $-0.02 \pm 0.57$ & 12.95 & $-0.30 \pm 0.64$ & 10.82 & 23.53 & Bern-II & BD-I \\
\hline Tringa nebularia & $1.47 \pm 0.49$ & 11.34 & $-0.21 \pm 1.95$ & 12.58 & $2.30 \pm 2.34$ & 10.44 & 23.16 & Bern-III & BD-II \\
\hline Tringa ochropus & $2.66 \pm 2.60$ & 9.28 & $-1.53 \pm 5.07$ & 10.52 & $-0.79 \pm 2.84$ & 8.39 & 21.10 & Bern-II & - \\
\hline Tringa stagnatilis & $0.03 \pm 0.03$ & 11.41 & $0.13 \pm 0.23$ & 12.64 & $0.60 \pm 1.95$ & 10.51 & 23.23 & Bern-II & - \\
\hline Tringa totanus & $-0.40 \pm 0.39$ & 3.67 & $-0.20 \pm 0.71$ & 4.90 & $-1.98 \pm 3.00$ & 2.77 & 15.48 & Bern-III & BD-II \\
\hline Uria aalge & $-0.10 \pm 0.21$ & -13.76 & $0.00 \pm 0.05$ & -12.53 & $0.00 \pm 0.01$ & -14.66 & -1.94 & Bern-III & BD-I \\
\hline Vanellus gregarius & $0.00 \pm 0.00$ & 7.52 & $0.00 \pm 0.05$ & 8.76 & $0.22 \pm 0.60$ & 6.63 & 19.34 & Bern-III & - \\
\hline Vanellus leucurus & $0.00 \pm 0.00$ & 5.06 & $0.00 \pm 0.05$ & 6.29 & $-0.01 \pm 0.01$ & 4.16 & 16.87 & Bern-III & - \\
\hline Vanellus spinosus & $0.00 \pm 0.00$ & 11.62 & $0.59 \pm 1.91$ & 12.86 & $2.40 \pm 6.32$ & 10.73 & 23.44 & Bern-III & BD-I \\
\hline Vanellus vanellus & $0.77 \pm 4.01$ & -7.30 & $-2.49 \pm 4.84$ & -6.06 & $-6.37 \pm 26.52$ & -8.20 & 4.52 & Bern-III & BD-II \\
\hline Xema sabini & $0.00 \pm 0.00$ & 10.20 & $0.00 \pm 0.05$ & 11.44 & $0.00 \pm 0.01$ & 9.30 & 22.02 & Bern-II & - \\
\hline Xenus cinereus & $0.00 \pm 0.00$ & 11.06 & $0.00 \pm 0.05$ & 12.30 & $-0.37 \pm 0.98$ & 10.17 & 22.88 & Bern-III & - \\
\hline
\end{tabular}


Table S2: Characteristics of the International Waterbird Census between countries and legal contexts. Since the European Union Member States and the Contracting Parties to the Bern Convention are mainly on the Northern Mediterranean shore, some heterogeneity in monitoring effort can occur between legal contexts. Characteristics per country are the first, the last and the average years of monitoring, the average number of monitored sites per year, the total number of species and the number of species which represent $95 \%$ of the abundance. We compared different characteristics of the International Waterbird Census between legal contexts using country information and Wilcoxon Mann Whitney test. Between legal contexts the differences in the average number of monitored sites per year as well as the total number of species were higher in BD-BC (Wilcoxon Mann Whitney, $\mathrm{p}<0.05$ ). The other characteristics were not significantly different between legal contexts (Wilcoxon Mann Whitney, $p>0.05$ ). ( $B C$ : countries that have ratified the Bern convention before or during the study period; No-BD No-BC: countries that have ratified neither the Birds Directive nor the Bern Convention).

\begin{tabular}{|c|c|c|c|c|c|c|c|c|}
\hline & $\begin{array}{l}\text { Legal contexts \& } \\
\text { Countries }\end{array}$ & $\begin{array}{l}\text { First } \\
\text { year }\end{array}$ & $\begin{array}{l}\text { Last } \\
\text { year }\end{array}$ & $\begin{array}{l}\text { Average year } \\
\quad( \pm S D)\end{array}$ & $\begin{array}{c}\text { Average } \\
\text { number of } \\
\text { sites per } \\
\text { year }\end{array}$ & $\begin{array}{l}\text { Number of } \\
\text { species }\end{array}$ & $\begin{array}{l}\text { Number of } \\
\text { species (95\% } \\
\text { abundance) }\end{array}$ & CTI $\beta_{\text {year }} \pm$ se \\
\hline & BD-BC & 1991.0 & 2012.0 & $2003 \pm 6$ & 183.6 & 112.2 & 55 & $0.04 \pm 0.00$ \\
\hline & France & 1991 & 2012 & $2003 \pm 6$ & 41.7 & 105 & 55 & $0.02 \pm 0.01$ \\
\hline & Greece & 1991 & 2012 & $2004 \pm 6$ & 59.6 & 111 & 56 & $0.08 \pm 0.01$ \\
\hline & Italy & 1991 & 2012 & $2002 \pm 6$ & 231.1 & 118 & 56 & $0.06 \pm 0.01$ \\
\hline & Portugal & 1991 & 2012 & $2005 \pm 7$ & 29.9 & 94 & 53 & $0.15 \pm 0.02$ \\
\hline & Spain & 1991 & 2012 & $2002 \pm 6$ & 555.6 & 133 & 55 & $0.02 \pm 0.00$ \\
\hline & $\mathrm{BC}$ & 1991.4 & 2012.0 & $2003 \pm 6$ & 21.0 & 77 & 47.8 & $0.05 \pm 0.01$ \\
\hline & Albania & 1993 & 2012 & $1999 \pm 5$ & 4.5 & 80 & 52 & $0.02 \pm 0.29$ \\
\hline & Bosnia \& Herz. & 1991 & 2012 & $2010 \pm 2$ & 25.7 & 39 & 31 & $0.11 \pm 0.19$ \\
\hline & Bulgaria & 1992 & 2012 & $2003 \pm 6$ & 39.4 & 93 & 54 & $0.09 \pm 0.12$ \\
\hline & Croatia & 1991 & 2012 & $2002 \pm 7$ & 9.0 & 68 & 47 & $0.03 \pm 0.02$ \\
\hline & Cyprus & 1991 & 2012 & $2005 \pm 6$ & 11.6 & 79 & 53 & $0.12 \pm 0.03$ \\
\hline & Macedonia & 1997 & 2012 & $2005 \pm 6$ & 2.2 & 38 & 29 & $0.02 \pm 0.05$ \\
\hline & Montenegro & 1991 & 2012 & $2004 \pm 7$ & 2.3 & 66 & 46 & $0.11 \pm 0.10$ \\
\hline & Morocco & 1991 & 2012 & $2001 \pm 7$ & 44.0 & 103 & 54 & $-0.02 \pm 0.01$ \\
\hline & Serbia & 1991 & 2012 & $2001 \pm 8$ & 4.7 & 46 & 31 & $0.21 \pm 0.04$ \\
\hline & Tunisia & 1991 & 2012 & $2004 \pm 7$ & 34.3 & 91 & 54 & $0.07 \pm 0.02$ \\
\hline & Turkey & 1992 & 2012 & $2003 \pm 7$ & 34.2 & 105 & 56 & $0.05 \pm 0.01$ \\
\hline & No BC-No BD & 1996.9 & 2007.4 & $2003 \pm 3$ & 20.4 & 61.6 & 40.9 & $-0.01 \pm 0.01$ \\
\hline & Algeria & 1991 & 2012 & $2004 \pm 6$ & 72.2 & 84 & 51 & $-0.02 \pm 0.01$ \\
\hline & Israel & 1991 & 2006 & $1999 \pm 5$ & 15.0 & 106 & 56 & $0.12 \pm 0.07$ \\
\hline & Jordan & 2001 & 2012 & $2007 \pm 3$ & 6.9 & 56 & 43 & $0.37 \pm 0.11$ \\
\hline & Lebanon & 2000 & 2003 & $2002 \pm 1$ & 3.7 & 31 & 31 & $0.68 \pm 0.76$ \\
\hline & Libya & 2005 & 2012 & $2008 \pm 2$ & 36.1 & 82 & 52 & $-0.07 \pm 0.06$ \\
\hline & Syria & 1993 & 1995 & $1994 \pm 1$ & 7.0 & 34 & 24 & $-0.28 \pm 0.18$ \\
\hline \multirow{4}{*}{$\begin{array}{l}\text { P-value Pairwise } \\
\text { Wilcoxon Mann } \\
\text { Whitney }\end{array}$} & BC vs. No BC-No BD & 0.130 & 0.031 & 1 & 0.023 & 0.660 & 0.511 & \\
\hline & $B C$ vs. $B C-B D$ & 0.160 & 1 & 1 & 0.503 & 0.016 & 0.078 & \\
\hline & BC-BD vs. No BC-No & & & & & & & \\
\hline & $\mathrm{BD}$ & 0.160 & 0.104 & 1 & 0.033 & 0.035 & 0.105 & \\
\hline
\end{tabular}


Table S3: CTI trends accounting for species composition and temporal bias. We computed CTI trends using i) species shared by the three legal contexts $(n=108$, species at least present in one of the country belong to 'BD-BC', 'BC' and 'No-BD No-BC'.), and ii) a reduced time period (1997-2007) corresponding to the average monitoring period of the No-BD No-BC legal context (1997-2007). We assessed the CTI trends using linear mixed effect models (one model legal context) with year (continuous) and $\mathrm{T}_{\text {mean }}$ as fixed effects, and site nested in country as a random effect. CTI trends by legal context were nearly the same accounting for the all dataset, the reduced monitoring period or only species shared by the three legal contexts (Significant trends are in bold, alpha < 0.05; BD-BC countries that have ratified both before the study period; $B C$ : countries that have ratified the Bern convention before or during the study period; No-BD No-BC: countries that have ratified neither the Birds Directive nor the Bern Convention).

\begin{tabular}{clrrrr}
\hline Analyses & \multicolumn{1}{c}{ Spatial scale } & \multicolumn{1}{c}{$\beta_{\text {year }} \pm$ se } & \multicolumn{1}{c}{$d f$} & \multicolumn{1}{c}{$t$} & \multicolumn{1}{c}{$p$} \\
\hline \multirow{3}{*}{ All data } & BD-BC & $\mathbf{0 . 0 4} \pm \mathbf{0 . 0 0}$ & $\mathbf{1 8 1 3 0}$ & $\mathbf{1 1 . 3 2}$ & $<\mathbf{0 . 0 0 1}$ \\
& BC & $\mathbf{0 . 0 5} \pm \mathbf{0 . 0 1}$ & $\mathbf{2 9 7 6}$ & $\mathbf{7 . 9 7}$ & $<\mathbf{0 . 0 0 1}$ \\
& No BC-No BD & $-0.01 \pm 0.01$ & 1727 & -0.98 & 0.328 \\
\hline \multirow{2}{*}{$\begin{array}{c}\text { Reduced monitoring } \\
\text { period 1997-2007 }\end{array}$} & BD-BC & $\mathbf{0 . 0 3} \pm \mathbf{0 . 0 1}$ & $\mathbf{9 1 2 6}$ & $\mathbf{4 . 4}$ & $<\mathbf{0 . 0 0 1}$ \\
& BC & $\mathbf{0 . 0 6} \pm \mathbf{0 . 0 2}$ & $\mathbf{1 0 5 3}$ & $\mathbf{3 . 4}$ & $<\mathbf{0 . 0 0 1}$ \\
& No BC-No BD & $0.01 \pm 0.03$ & 888 & 0.2 & 0.811 \\
\hline Species shared by & BD-BC & $\mathbf{0 . 0 4} \pm \mathbf{0 . 0 0}$ & $\mathbf{1 8 1 1 7}$ & $\mathbf{1 0 . 6}$ & $<0.001$ \\
the three legal & BC & $\mathbf{0 . 0 5} \pm \mathbf{0 . 0 1}$ & $\mathbf{2 9 7 6}$ & $\mathbf{7 . 6}$ & $<\mathbf{0 . 0 0 1}$ \\
contexts & No BC-No BD & $-0.01 \pm 0.01$ & 1727 & -0.49 & 0.348 \\
\hline
\end{tabular}


Table S4: Species contribution of cold vs. warm-dwelling species depending of species protection status and legal context. To test whether cold-dwelling or warm-dwelling species are driving the CTI increase, we compared for each legal context and for each protection status the difference in contribution between cold and warm-dwelling species. To do so, for each case, we used an LMM with the species contribution as the response variable and cold vs. warm-dwelling categories as fixed effects. Species identity was added as random factor and spatial autocorrelation was taken into account with an exponential structure on the centroid of each country based on sites coordinates. The only significant difference in contribution was found in strictly protected species in 'BD-BC' countries: strictly protected warm-dwelling species in 'BD-BC' contribute more to the $\mathrm{CTI}$ increase than strictly protected cold-dwelling species in 'BD-BC' (Significant trends are in bold, alpha $<0.05 ; \beta$ corresponds to the difference in contribution between cold and warm-dwelling species; $B D-B C$ countries that have ratified both before the study period; $B C$ : countries that have ratified the Bern convention before or during the study period; No-BD No-BC: countries that have ratified neither the Birds Directive nor the Bern Convention).

\begin{tabular}{cccccc}
\hline Legal context & Protection status & $\beta \pm \mathrm{se}$ & $\mathrm{df}$ & $\mathrm{t}$ & $\mathrm{p}$ \\
\hline \multirow{2}{*}{$\mathrm{BD}-\mathrm{BC}$} & Strict & $\mathbf{0 . 9 9} \pm \mathbf{0 . 4 6}$ & $\mathbf{3 2 7}$ & $\mathbf{2 . 1 6}$ & $\mathbf{0 . 0 3}$ \\
\cline { 2 - 6 } & Not Strict & $-0.73 \pm 0.50$ & 251 & -1.47 & 0.14 \\
\hline \multirow{2}{*}{$\mathrm{BC}$} & Strict & $0.49 \pm 0.37$ & 672 & 1.35 & 0.18 \\
\cline { 2 - 6 } & Not Strict & $0.27 \pm 0.59$ & 620 & 0.45 & 0.65 \\
\hline \multirow{2}{*}{ No-BD No-BC } & Strict & $0.51 \pm 0.32$ & 443 & 1.59 & 0.11 \\
\cline { 2 - 6 } & Not Strict & $0.23 \pm 0.50$ & 425 & 0.45 & 0.65 \\
\hline
\end{tabular}


Figure S1: Species contribution to the CTI increase and their relative thermic originality for the two legal contexts: ' $B C$ ' and 'No-BD No-BC', $(A)$ in the ' $B C$ ' ratifying parties and $(B)$ in the 'No-BD No- $B C$ ' ratifying parties, for the strictly and not strictly protected species (cf. Fig. 3B for ' $B D-B C$ '). The ' $N$ ' refers to the number of points per quadrant used to determine the density, i.e. species contributing at least at $0.5 \%$ per country. The $X$ axis scale was presented with arc sinus transformation to facilitate the reading. The division in four quadrants according to the sign (plus/minus) of the relative species thermic originality and the sign of the species contribution correspond to four configurations revealing the relative population increase or decrease (Fig. 3A) (BD-BC countries that have ratified both before the study period; $\mathrm{BC}$ : countries that have ratified the Bern convention before or during the study period; No-BD No-BC: countries that have ratified neither the Birds Directive nor the Bern Convention).
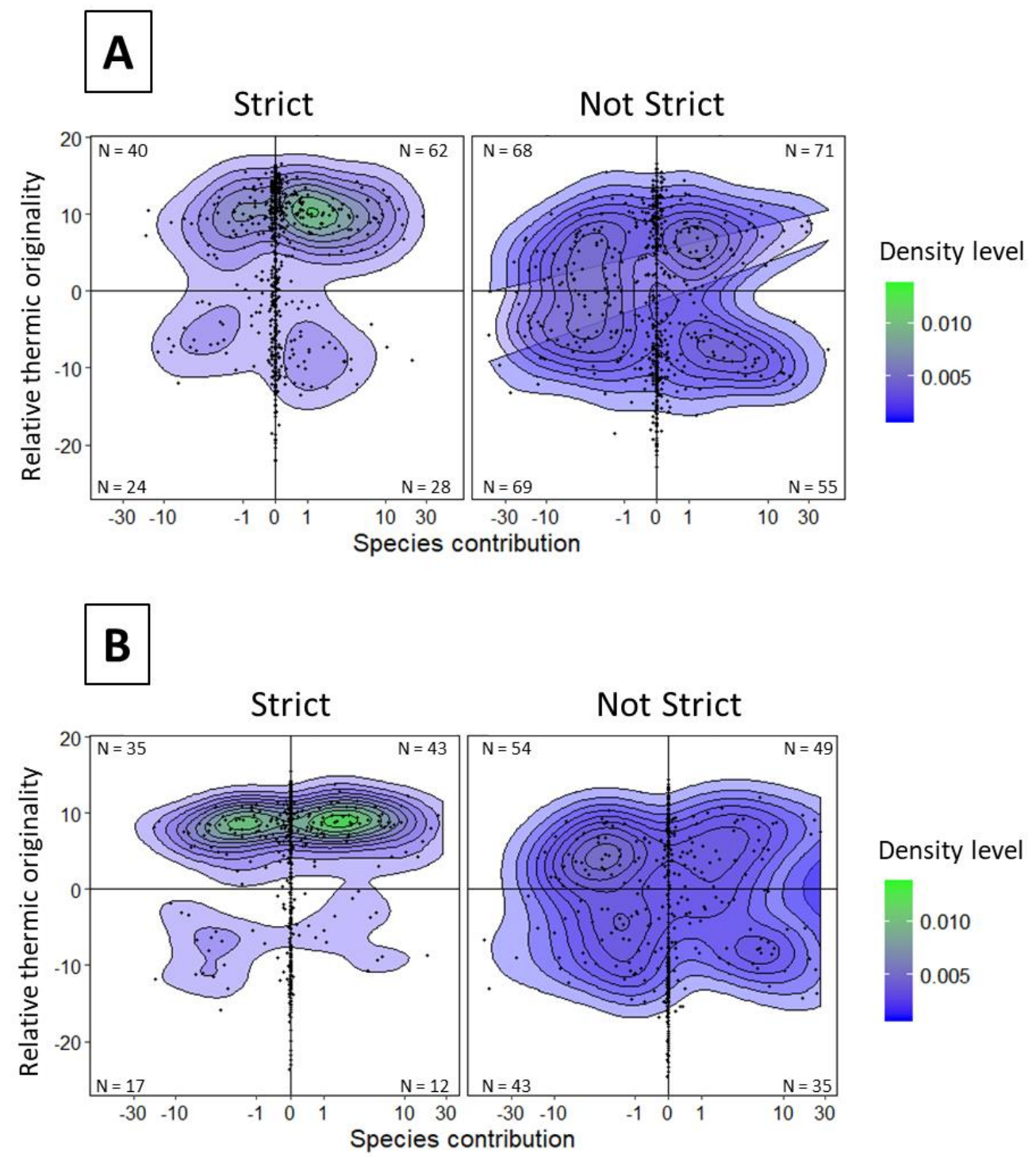